\title{
Enhanced Stretchable and Sensitive Strain Sensor via Controlled Strain Distribution
}

\author{
Huamin Chen ${ }^{1, *(\mathbb{D})}$, Longfeng $\mathrm{Lv}^{2}$, Jiushuang Zhang ${ }^{2}$, Shaochun Zhang ${ }^{2}$, Pengjun $\mathrm{Xu}^{3}{ }^{3}$, \\ Chuanchuan $\mathrm{Li}^{2}$, Zhicheng Zhang ${ }^{1}$, Yuliang $\mathrm{Li}^{1}$, Yun $\mathrm{Xu}^{2, *}$ and Jun Wang ${ }^{1, *}$ \\ 1 Fujian Provincial Key Laboratory of Functional Marine Sensing Materials, Center for Advanced Marine \\ Materials and Smart Sensors, Minjiang University, Fuzhou 350108, China; zhicheng@mju.edu.cn (Z.Z.); \\ liyuliang@mju.edu.cn (Y.L.) \\ 2 Institute of Semiconductors, Chinese Academy of Sciences, Beijing 100083, China; lflv@semi.ac.cn (L.L.); \\ jszhang@semi.ac.cn (J.Z.); sczhang@semi.ac.cn (S.Z.); lichuan@semi.ac.cn (C.L.) \\ 3 Faculty of Clothing and Design, Minjiang University, Fuzhou 350108, China; xupj@mju.edu.cn \\ * Correspondence: chenhuamin@semi.ac.cn (H.C.); xuyun@semi.ac.cn (Y.X.); wjnaf@163.com (J.W.)
}

Received: 26 December 2019; Accepted: 21 January 2020; Published: 27 January 2020

\begin{abstract}
Stretchable and wearable opto-electronics have attracted worldwide attention due to their broad prospects in health monitoring and epidermal applications. Resistive strain sensors, as one of the most typical and important device, have been the subject of great improvements in sensitivity and stretchability. Nevertheless, it is hard to take both sensitivity and stretchability into consideration for practical applications. Herein, we demonstrated a simple strategy to construct a highly sensitive and stretchable graphene-based strain sensor. According to the strain distribution in the simulation result, highly sensitive planar graphene and highly stretchable crumpled graphene (CG) were rationally connected to effectively modulate the sensitivity and stretchability of the device. For the stretching mode, the device showed a gauge factor (GF) of 20.1 with $105 \%$ tensile strain. The sensitivity of the device was relatively high in this large working range, and the device could endure a maximum tensile strain of $135 \%$ with a GF of 337.8. In addition, in the bending mode, the device could work in outward and inward modes. This work introduced a novel and simple method with which to effectively monitor sensitivity and stretchability at the same time. More importantly, the method could be applied to other material categories to further improve the performance.
\end{abstract}

Keywords: stretchable; strain sensor; graphene; sensitive; strain distribution

\section{Introduction}

Stretchable and wearable electronics have attracted tremendous interest due to their broad prospects in health monitoring and epidermal applications. Various stretchable devices such as displays [1,2], integrated circuits [3,4], energy conversion and storage units [5-8], and sensing systems $[9,10]$ have been developed to improve practicality. As one of the most important and typical devices, strain sensors have been the subject of remarkable progress in terms of sensing mechanisms including strain-resistance effect [11-17], strain-capacitance effect [18-23], thermoelectric effect [24,25], piezoelectric effect [26-30], triboelectric effect [31-35], and field effect [36-38]. There are also other methods for strain sensing based on polymer optical fibers [39-41]. Resistive strain sensors stand out from these other types of device due to their excellent characteristics, including abundant material source, simple fabrication process, high gauge factor, and easy integration. Many efforts have been made to improve their sensitivity and stretchability for practical applications. To date, the sensitivity of the resistive strain sensor has reached over 5000 [42-44], and the stretchability has exceeded $900 \%$ [45-47]. 
Various materials including organic materials [48,49], carbon materials [50,51], metal materials [52,53], semiconductor materials [54,55], and hybrid materials [56,57] have been utilized to fabricate resistive strain sensors with better performance. Diverse novel materials have been introduced to enhance device sensitivity. Instead of traditional materials, nanowires or nanofibers are usually adopted [11,17]. Cracks can also be introduced into the material to effectively increase the sensitivity $[13,44]$. Alongside sensitivity, stretchability is equally important. Microstructures such as crumple structures, zigzag structures, U-shape structures, and mesh layout are usually introduced into the conductor surface to form highly stretchable strain sensors [58,59]. In addition, intrinsic stretchable materials such as ionic conductive hydrogel can be selected to improve device stretchability $[45,47,60]$. Nevertheless, it is hard to take both sensitivity and stretchability into consideration at the same time. Ultrasensitive and highly stretchable resistive strain sensors are still a great challenge.

In this work, we demonstrated a straightforward method by which to fabricate a highly sensitive and stretchable graphene-based strain sensor. By connection of planar graphene and crumpled graphene (CG) films with various crumple degrees, we were able to effectively modulate the sensitivity and stretchability of the device. For stretching mode, the device was made up of two CG nanosheets with planar graphene between them. This device showed a gauge factor (GF) of 20.1 with 105\% tensile strain, and it could endure a maximum tensile strain of $135 \%$ with a GF of 337.8 . In addition, for bending mode, the device consisted of two planar graphene films with a CG film between them. The device could work in outward and inward modes. This work introduced a novel and simple strategy by which to effectively monitor sensitivity and stretchability at the same time. More importantly, the strategy could be applied to other material categories.

\section{Materials and Methods}

\subsection{Fabrication of the Highly Stretchable and Sensitive Strain Sensor}

Graphene grown on a copper substrate was transferred onto a polydimethylsiloxane (PDMS) thin film by transfer printing method. Two graphene/PDMS films were then attached to a uniaxially pre-stretched very-high-bond (VHB) film. The graphene was left on the pre-stretched VHB after peeling the PDMS film, as shown in Figure 1a. After releasing the pre-strain, two CG sheets formed the VHB film, leaving a gap in the middle. Later, a planar graphene film was transferred onto the VHB film which was located in the middle of the two CG regions. The planar graphene sheet covered the blank area. Finally, a stretchable and sensitive strain sensor was achieved after leading wire and packaging, as illustrated in Figure 1b. A photograph of the highly flexible device is shown in Figure 1c. This device structure was mainly designed for tensile applications. In addition, bending situations are normal in joint movement. A structure of planar graphene/CG/planar graphene was then improved for bending applications. Schematic illustrations of the tensile and bending tests are shown in Figure 1d,e.

\subsection{Characterization of the Device}

The surface structure of the materials was characterized using a scanning electron microscope (SEM, Quanta 450, FEI Company, Hillsborough, CA, USA), and the resistance was measured using a multimeter (DMM 7510, Keithley, Cleveland, OH, USA). The stability test and the current-voltage curve of the device were assessed using a semiconductor characterization system (B1500A, Agilent, Santa Clara, CA, USA) with commercial slides. 

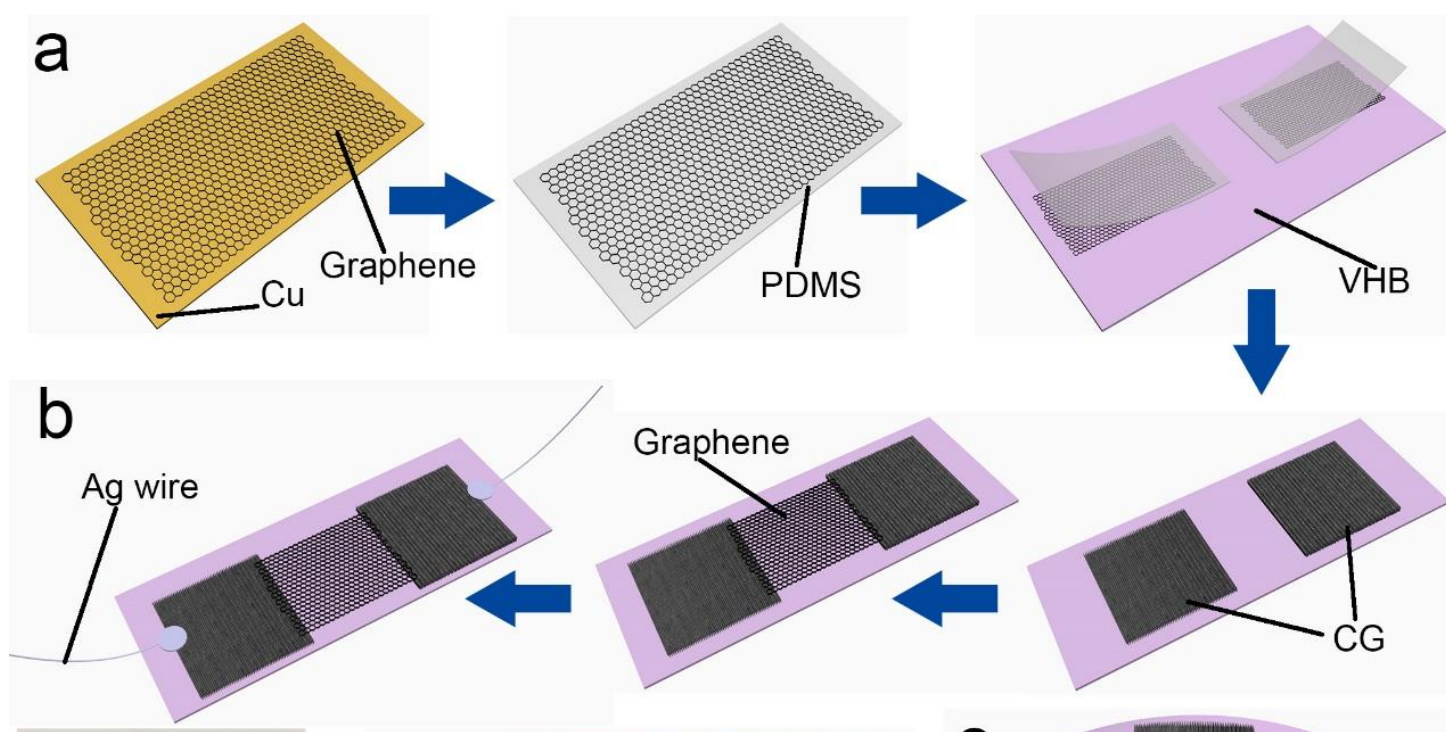

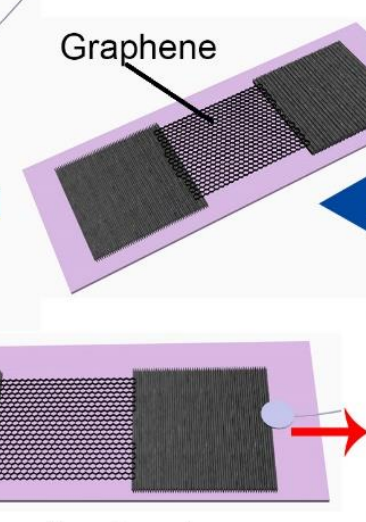

Tensile test

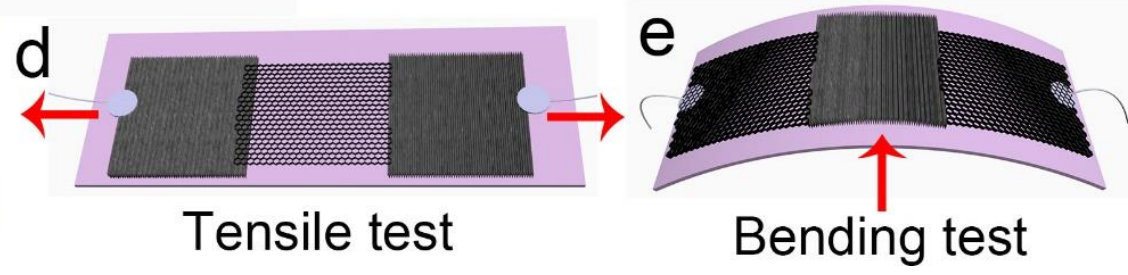

Figure 1. Schematic diagram of the fabrication process of the highly sensitive and stretchable strain sensor. (a) The transfer printing of graphene. (b) The fabrication process of a strain sensor.

(c) Photograph of the flexible device. (d) Schematic diagram of the strain sensor under tensile testing.

(e) Schematic diagram of the strain sensor under bending testing.

\section{Results and Discussion}

First, the surface morphology of the device was analyzed, as shown in Figure 2. Figure 2a shows the SEM picture of graphene (left) and CG (right) on the substrate. Under a uniaxially pre-strained situation, parallel ridges were discovered on the surface. The crumples and buckles supported the stretchability, as shown on the right side of Figure 2a. During fabrication of the strain sensor, the graphene was directly attached onto the CG. The CG on the VHB film affected the transfer printing quality of the graphene because it made the VHB less sticky. Work function differences between the graphene and CG were possible, so it was necessary to analyze the homojunction of graphene/CG. The contact resistance test was performed using the Agilent B1500A and the results are exhibited in Figure $2 \mathrm{~b}$. From the I-V curve of graphene/CG, the homojunction was ohmic contact, and the contact resistance was about $3 \mathrm{k} \Omega$. The ohmic contact of graphene/CG offers benefits not only for the strain sensor, but also for other electronic applications.

To rationally design the parameters of the device, we simulated the strain distribution of the device under tensile strains, as shown in Figure 3. Figure 3a shows the strain distribution of the device under tensile strain. The size of the device was $2.0 \mathrm{~cm}$ in length and $0.5 \mathrm{~cm}$ in width. The two ends of the device (up and down) were fixed, and the other two ends were stretched. We ran a finite element analysis calculation to simulate the strain distribution. The Young's modulus and the Poisson's ratio in this simulation were $1 \times 10^{6} \mathrm{~Pa}$ and 0.49 , respectively. It was clearly observed that the strain in both ends of the device was relatively larger, while it was very small in the middle area. The simulation result shown in Figure 3a was correlated with our previous work [51]. The detailed strain distribution is displayed in Figure 3b. Under a tensile strain of 50\%, the strain in the middle position was only about $24 \%$. According to the strain distribution in the simulation, we designed the device structure by combining two types of strain sensor. One was the highly stretchable strain sensor with a small GF, which was located on the two ends of the VHB. The other was the highly sensitive strain sensor 
with a narrow working range. To extend the working range of the strain sensor without sacrificing its sensitivity, planar graphene and CG were combined in a rationally designed structure.
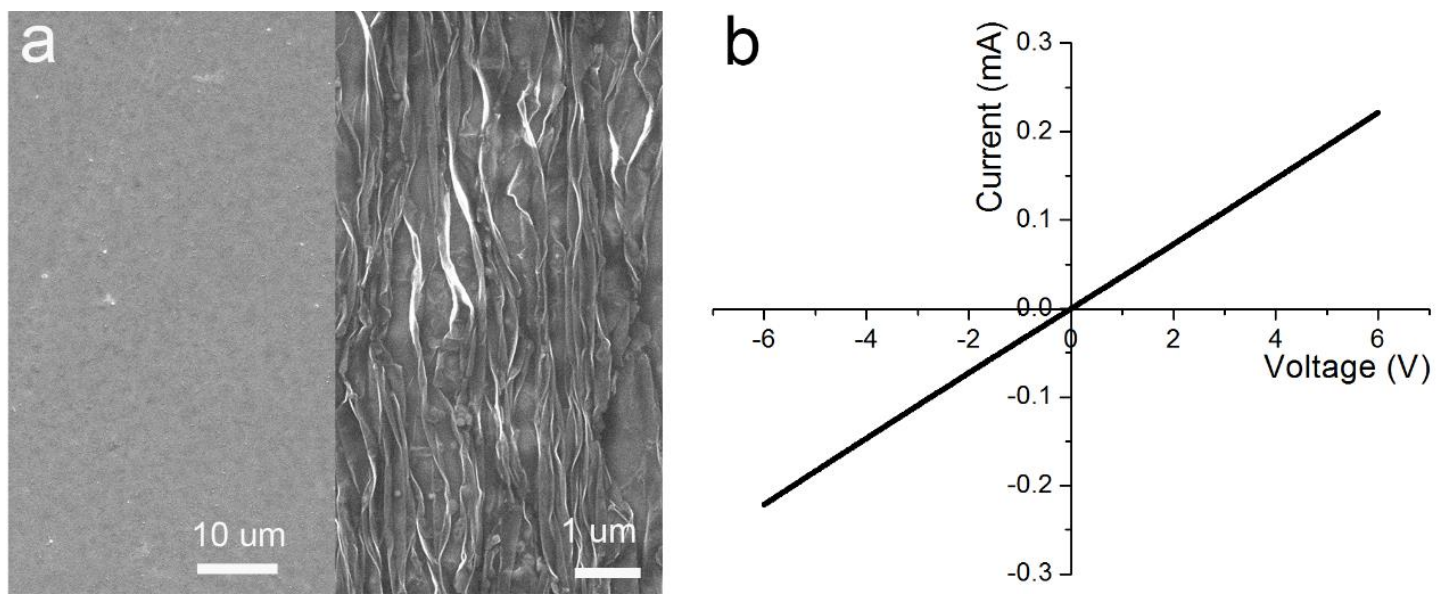

Figure 2. The interface characteristics of the graphene/crumpled graphene (CG). (a) The SEM pictures of the graphene and CG. (b) I-V curve of the graphene/CG junction.
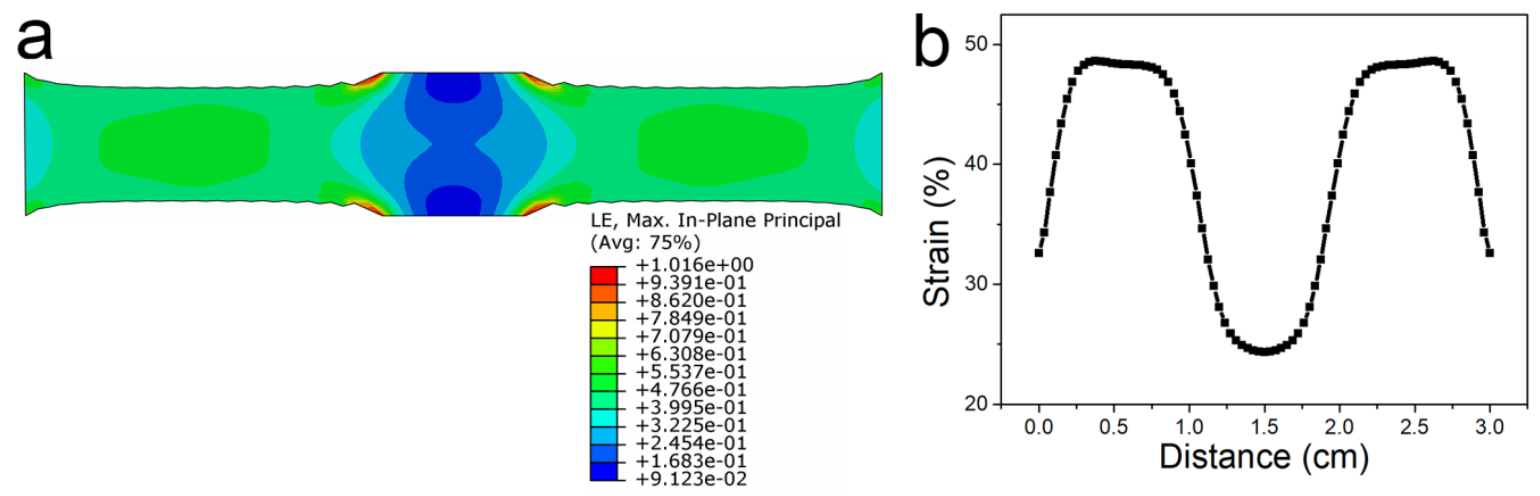

Figure 3. The mechanical simulation of the device. (a) The simulation of the strain sensor under uniaxial stretching. (b) The strain distribution of the strain sensor under simulated stretching.

The electromechanical properties of the strain sensors with various crumple degree are characterized in Figure 4. The crumple degree was defined as $\varepsilon_{\text {pre }}=\left(L_{S}-L_{P}\right) / L_{P}$ where $L_{S}$ and $L_{\mathrm{P}}$ are the pre-stretched length and pristine length of VHB. The strain sensors with different $\varepsilon_{\text {pre }}$ values showed significant differences in resistance-strain relationships, as shown in Figure 4a. The strain sensor based on planar graphene exhibited high sensitivity but poor stretchability. Under $10 \%$ tensile strain, cracks appeared on the graphene, which greatly increased its resistance. The sensitivity was characterized by the gauge factor (GF), which is defined as

$$
\mathrm{GF}=\frac{\Delta \mathrm{R} / \mathrm{R}_{0}}{\varepsilon}
$$

where $\Delta R$ and $R_{0}$ are the resistance variation under tensile strain and the pristine resistance with no strain, respectively, and $\varepsilon$ is the tensile strain applied to the sensor. The GF of all the strain sensors was calculated by linear fit. 

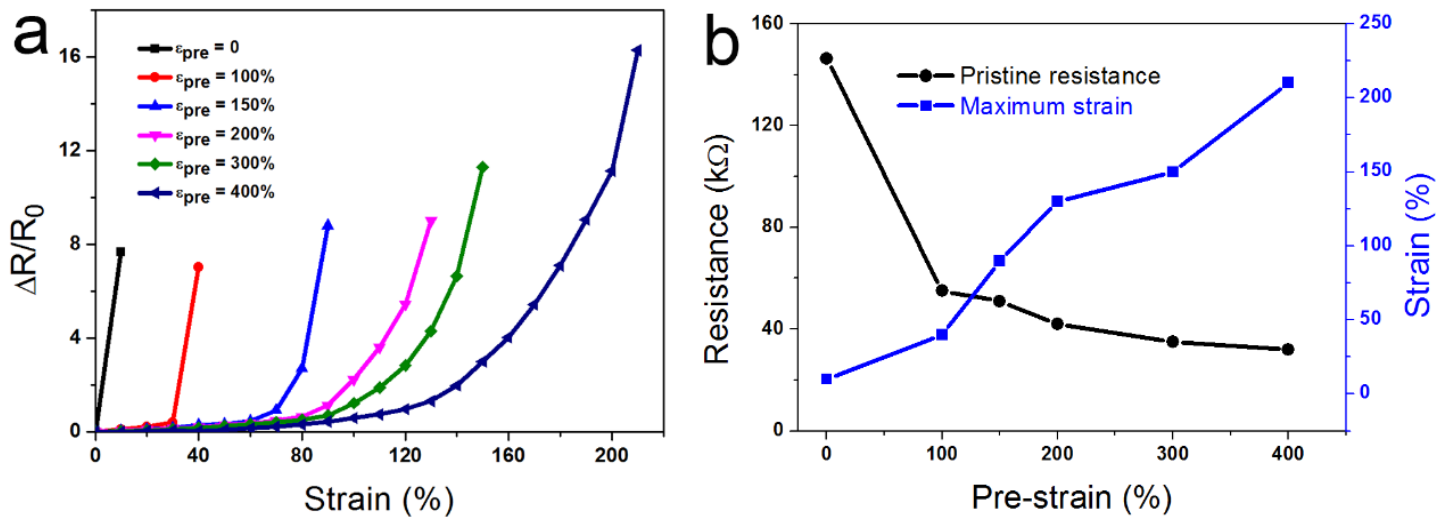

Figure 4. The electromechanical properties of various strain sensors. (a) The relationship between the resistance variation and strain with various pre-strains. (b) The resistance and the maximum endurable strain comparison of various strain sensors with different pre-strains.

Generally, the planar graphene was not able to endure $10 \%$ tensile strain. In this experiment, this was due to the wavy structure formed while transferring the planar graphene onto the VHB film. The strain sensor based on the CG showed better stretchability compared to the planar device. Furthermore, its working range under tensile strain was increased with increasing $\varepsilon_{\text {pre }}$. The detailed characteristic of these sensors with various $\varepsilon_{\text {pre }}$ was listed in Table 1 . The strain sensors with $\varepsilon_{\text {pre }}$ values from $100 \%$ to $400 \%$ exhibited a GF of about 1 . Although the stretchability increased gradually, the sensitivity was low. Furthermore, the linear correlation $\left(\mathrm{R}^{2}\right)$ decreased as the stretchability increased, meaning that the GF was further decreased in the same linear fit range. Errors may have been introduced in the linear fit. It should be noted that the limit of the VHB is about $500 \%$, and our device approached this limit. The pristine resistance and the maximum tolerant strain of these strain sensors is displayed in Figure $4 \mathrm{~b}$. The pristine resistance of the planar graphene was about $150 \mathrm{k} \Omega$ and the resistance decreased rapidly

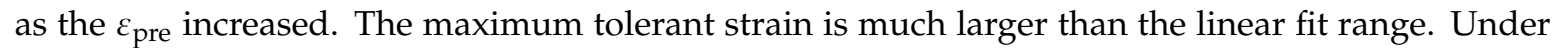
the maximum strain, the resistance of the sensor exceeded the measurement range of the multimeter $(100 \mathrm{M} \Omega)$.

Table 1. Comparison of various strain sensors with different pre-strains.

\begin{tabular}{cccc}
\hline Pre-Strain Degree & Linear Fit Range & $\mathbf{R}^{\mathbf{2}}$ & GF \\
\hline $100 \%$ & $0-30 \%$ & 0.97474 & 1.31 \\
$150 \%$ & $0-60 \%$ & 0.96328 & 0.779 \\
$200 \%$ & $0-80 \%$ & 0.93992 & 0.753 \\
$300 \%$ & $0-90 \%$ & 0.91959 & 0.734 \\
$400 \%$ & $0-110 \%$ & 0.8364 & 0.641 \\
\hline
\end{tabular}

The properties of the designed strain sensor are characterized in Figure 5. The device was fixed to a commercial slide, as shown in Figure 5a. First, we measured the resistance variation of the device under various tensile strains. The relationship between the $\Delta R / R_{0}$ and $\varepsilon$ is exhibited in Figure $5 b$. With small strains $(\varepsilon<105 \%)$, the resistance increased slowly due to the stretchability of the crumple structure. The GF obtained by the linear fit was 20.1. As we continued to increase the strain ( $\varepsilon \geq 105 \%$ ), cracks were formed. These cracks led to a rapid resistance increase. The sharp change of the resistance resulted in a high GF of 337.8. It should be noted that once small cracks had been formed, the device could not fully recover to its original state. Thus, the effective working range of the device was $105 \%$. The key parameters are displayed in Table 2. 

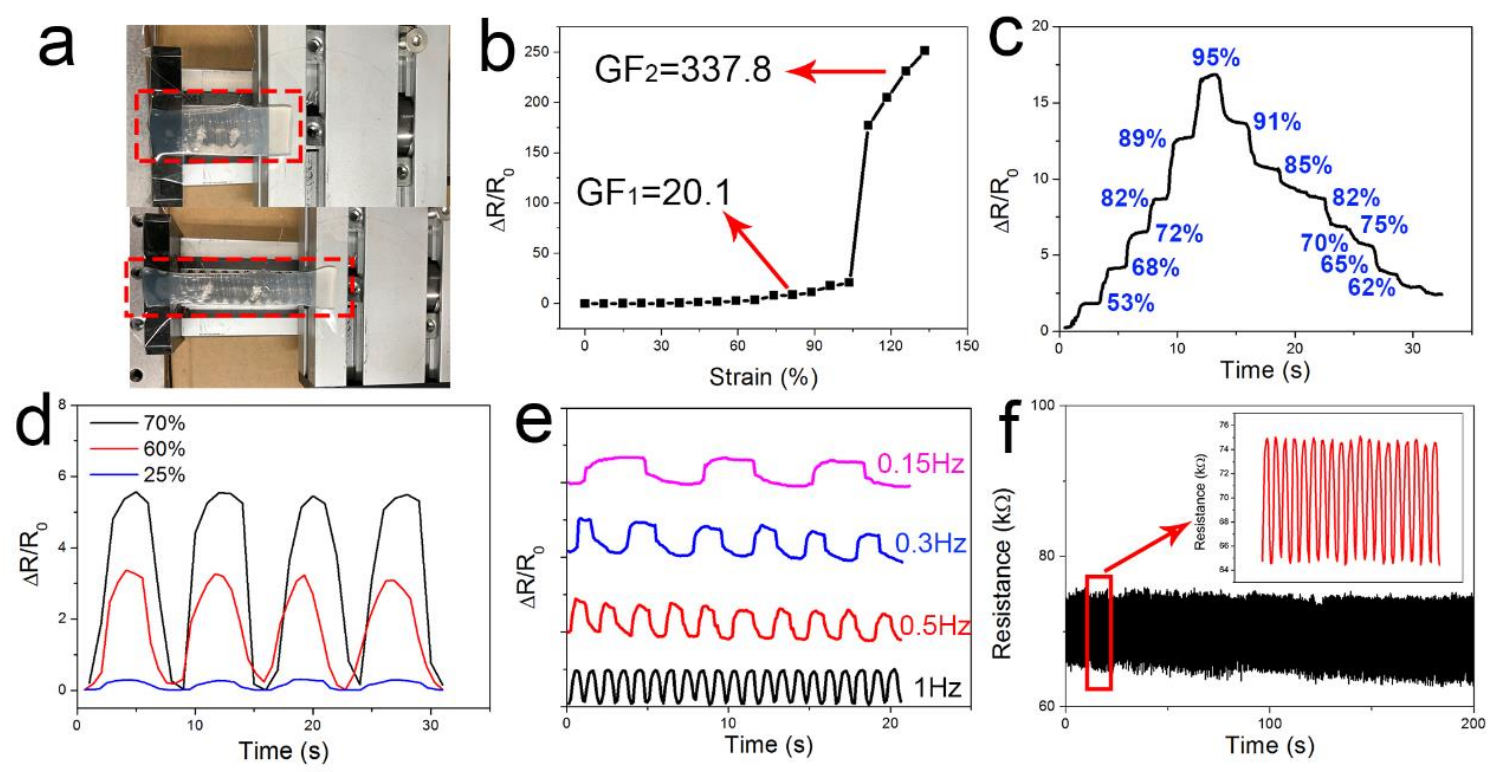

Figure 5. The characteristics of the strain sensor under stretching mode. (a) Experimental pictures of the device. (b) Resistance variation of the device under various tensile strain. (c) Resistance variation of the device under tensile strain and released conditions. (d) Response of the strain sensor under various strain conditions. (e) Response of the strain sensor under different frequency conditions. (f) Stability test of the device.

Table 2. The key parameters of this strain sensor.

\begin{tabular}{ccc}
\hline Linear Fit Range & $\mathbf{R}^{\mathbf{2}}$ & GF \\
\hline $0-105 \%$ & 0.9138 & 20.1 \\
$105-135 \%$ & 0.9764 & 337.8 \\
\hline
\end{tabular}

The typical response curve of the device is displayed in Figure 5c. The resistance needed enough time to return to its original state, so the curve is a little slanted. The device was first stretched to $95 \%$, and then the strain was gradually released. In the stretching process, the resistance increased as the tensile strain increased from $53 \%$ to $95 \%$ and the resistance was stable. In the releasing process, the resistance started to recover. As it took time to return to its original state, the resistance exhibited as a slope. In addition, we performed multiple loading-unloading tests under different tensile strains of $25 \%, 60 \%$ and $70 \%$, respectively. The results are shown in Figure $5 \mathrm{~d}$. The variation of the resistance under various frequencies is displayed in Figure 5e. The curves showed good repeatability. Finally, stability tests were performed, as shown in Figure 5f. From Figure 5, we can see that the sensitivity of the device was 20.1 in the working range of $105 \%$ and 337.8 in the range of from $105 \%$ to $135 \%$. To date, the GF of the ultrasensitive strain sensor was about 40,000 [42] and the stretchability of the ultra-stretchable strain sensor reached up to 950\% [47]. Although the sensitivity or the working range did not reach best possible level, it did reach a high level and show good potential in both areas at the same time. More important, it possessed the potential to modulate the sensitivity and stretchability of the device for various practical applications.

Furthermore, we designed another device for bending applications. The structure of the device was planar graphene/CG/planar graphene. The experimental results were shown in Figure 6. The device was attached onto a flexible thin film for the bending test. The bending radius of the device was controlled by a commercial slide, as shown in Figure 6a. The results of the bending test are exhibited in Figure $6 \mathrm{~b}, \mathrm{c}$. In the outward bending test, the $\Delta \mathrm{R} / \mathrm{R}_{0}$ increased from $0.4 \%$ to $15.1 \%$ as the bending radius decreased from $6.3 \mathrm{~cm}$ to $1.7 \mathrm{~cm}$. As the bending radius decreased from $2.4 \mathrm{~cm}$ to $1.7 \mathrm{~cm}$, the resistance of the device increased rapidly. In the inward bending test, the $\Delta R / R_{0}$ got up to $-3 \%$ as the 
bending radius deceased to $2.9 \mathrm{~cm}$. The resistance did not continue decreasing as we further decreased the bending radius. The decreased resistance was due to the overlap of the crumpled graphene films. The newly formed path decreased the resistance. A stability test was conducted and the results are shown in Figure 6d. The resistance here was relatively higher than that in Figure $5 \mathrm{f}$. This was due to the different structural design. The device contained more planar graphene, which has a higher resistance than that of CG. This device is suitable for wearable applications such as monitoring joint movement.
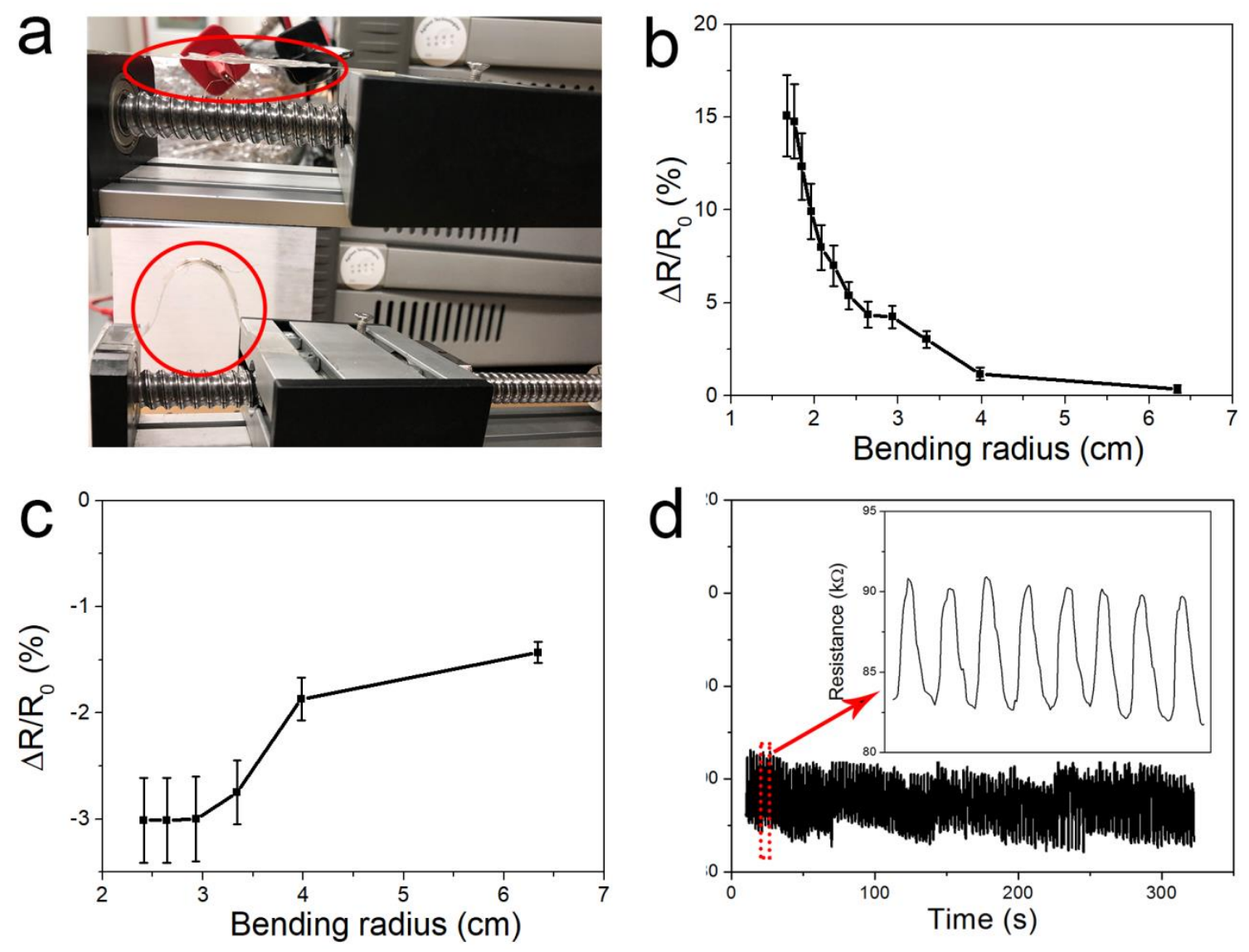

Figure 6. The characteristics of the device under bending condition. (a) Pictures of the test experiment. The resistance variation of the strain sensor under different bending radii of $(\mathbf{b})$ outward bending and (c) inward bending. (d) Stability test of the device.

\section{Conclusions}

In summary, we demonstrated a straightforward method by which to construct a flexible strain sensor with high sensitivity and stretchability. According to the strain distribution in the simulation results, the strain was small in the middle area while it was large at both ends. The sensitivity and stretchability of the device could be effectively controlled by rational connection of planar graphene and CG. For stretching applications, the device was made up of two CG nanosheets with a planar graphene film between them. This device showed a GF of 20.1 at the working range of $105 \%$, and it could bear a maximum tensile strain of $105 \%$ with a GF of 337.8. In addition, for the bending mode, the device consisted of two planar graphene films with CG between them, which revealed good stability. This work introduced a novel and simple strategy to effectively monitor sensitivity and stretchability at the same time. More importantly, the strategy could be applied to other material categories to further enhance the performance of strain sensors. The sensitive and stretchable sensor is promising for wearable applications and epidermal applications, especially in joint monitoring. 
Author Contributions: Conceptualization, H.C.; methodology, P.X. and L.L.; validation, Y.L. and H.C.; formal Analysis, J.Z.; investigation, H.C., S.Z., C.L. and Z.Z.; writing-original draft preparation, H.C.; writing-review and editing, H.C. and Y.X.; supervision, J.W. All authors have read and agree to the published version of the manuscript.

Funding: This work was supported by the National Natural Science Foundation of China (Nos. 11674185, 61835011), the Natural Science Foundation of Fujian (Nos. 2019J01764 and 2019J05110) and the Natural Science Foundation of Ningbo (2018A610007).

Acknowledgments: The authors acknowledge the 6Carbon Technology (Shenzhen) for providing graphene.

Conflicts of Interest: The authors declare no conflict of interest.

\section{References}

1. Park, S.I.; Xiong, Y.; Kim, R.H.; Elvikis, P.; Meitl, M.; Kim, D.H.; Wu, J.; Yoon, J.; Yu, C.J.; Liu, Z.; et al. Printed assemblies of inorganic light-emitting diodes for deformable and semitransparent displays. Science 2009, 325, 977-981. [CrossRef]

2. Li, S.; Peele, B.N.; Larson, C.M.; Zhao, H.; Shepherd, R.F. A Stretchable Multicolor Display and Touch Interface Using Photopatterning and Transfer Printing. Adv. Mater. 2016, 28, 9770-9775. [CrossRef]

3. Kim, D.H.; Ahn, J.H.; Choi, W.M.; Kim, H.S.; Kim, T.H.; Song, J.; Huang, Y.Y.; Liu, Z.; Lu, C.; Rogers, J.A. Stretchable and foldable silicon integrated circuits. Science 2008, 320, 507-511. [CrossRef] [PubMed]

4. Cheng, Y.; Wang, R.; Sun, J.; Gao, L. Highly conductive and ultrastretchable electric circuits from covered yarns and silver nanowires. ACS Nano 2015, 9, 3887-3895. [CrossRef] [PubMed]

5. Liu, W.; Song, M.-S.; Kong, B.; Cui, Y. Flexible and Stretchable Energy Storage: Recent Advances and Future Perspectives. Adv. Mater. 2016, 29, 1603436. [CrossRef] [PubMed]

6. Xu, S.; Zhang, Y.; Cho, J.; Lee, J.; Huang, X.; Jia, L.; Fan, J.A.; Su, Y.; Su, J.; Zhang, H.; et al. Stretchable batteries with self-similar serpentine interconnects and integrated wireless recharging systems. Nat. Commun. 2013, 4, 1543. [CrossRef]

7. Rojas, J.P.; Singh, D.; Conchouso, D.; Arevalo, A.; Foulds, I.G.; Hussain, M.M. Stretchable helical architecture inorganic-organic hetero thermoelectric generator. Nano Energy 2016, 30, 691-699. [CrossRef]

8. Lee, J.; Lee, K.Y.; Gupta, M.K.; Kim, T.Y.; Lee, D.; Oh, J.; Ryu, C.; Yoo, W.J.; Kang, C.; Yoon, S.; et al. Highly Stretchable Piezoelectric-Pyroelectric Hybrid Nanogenerator. Adv. Mater. 2014, 26, 765-769. [CrossRef]

9. Ko, H.C.; Stoykovich, M.P.; Song, J.; Malyarchuk, V.; Choi, W.M.; Yu, C.J.; Geddes, J.B.; Xiao, J.; Wang, S.; Huang, Y.; et al. A hemispherical electronic eye camera based on compressible silicon optoelectronics. Nature 2008, 454, 748-753. [CrossRef]

10. Kim, D.H.; Lu, N.; Ma, R.; Kim, Y.S.; Kim, R.H.; Wang, S.; Wu, J.; Won, S.M.; Tao, H.; Islam, A.; et al. Epidermal electronics. Science 2011, 333, 838-843. [CrossRef]

11. Gong, S.; Schwalb, W.; Wang, Y.; Chen, Y.; Tang, Y.; Si, J.; Shirinzadeh, B.; Cheng, W. A wearable and highly sensitive pressure sensor with ultrathin gold nanowires. Nat. Commun. 2014, 5, 3132. [CrossRef] [PubMed]

12. Yin, B.; Liu, X.; Gao, H.; Fu, T.; Yao, J. Bioinspired and bristled microparticles for ultrasensitive pressure and strain sensors. Nat. Commun. 2018, 9, 5161. [CrossRef] [PubMed]

13. Kang, D.; Pikhitsa, P.V.; Choi, Y.W.; Lee, C.; Shin, S.S.; Piao, L.; Park, B.; Suh, K.-Y.; Kim, T.-I.; Choi, M. Ultrasensitive mechanical crack-based sensor inspired by the spider sensory system. Nature 2014, 516, 222-226. [CrossRef] [PubMed]

14. Park, J.J.; Hyun, W.J.; Mun, S.C.; Park, Y.T.; Park, O.O. Highly stretchable and wearable graphene strain sensors with controllable sensitivity for human motion monitoring. ACS Appl. Mater. Interfaces 2015, 7, 6317-6324. [CrossRef] [PubMed]

15. Yamada, T.; Hayamizu, Y.; Yamamoto, Y.; Yomogida, Y.; Izadi-Najafabadi, A.; Futaba, D.N.; Hata, K. A stretchable carbon nanotube strain sensor for human-motion detection. Nat. Nanotechnol. 2011, 6, $296-301$. [CrossRef]

16. Liao, X.; Zhang, Z.; Liao, Q.; Liang, Q.; Ou, Y.; Xu, M.; Li, M.; Zhang, G.; Zhang, Y. Flexible and printable paper-based strain sensors for wearable and large-area green electronics. Nanoscale 2016, 8, 13025-13032. [CrossRef]

17. Pang, C.; Lee, G.-Y.; Kim, T.-I.; Kim, S.M.; Kim, H.N.; Ahn, S.-H.; Suh, K.-Y. A flexible and highly sensitive strain-gauge sensor using reversible interlocking of nanofibres. Nat. Mater. 2012, 11, 795-801. [CrossRef] 
18. Lipomi, D.J.; Vosgueritchian, M.; Tee, B.C.K.; Hellstrom, S.L.; Lee, J.A.; Fox, C.H.; Bao, Z. Skin-like pressure and strain sensors based on transparent elastic films of carbon nanotubes. Nat. Nanotechnol. 2011, 6, 788-792. [CrossRef]

19. Larson, C.; Peele, B.; Li, S.; Robinson, S.; Totaro, M.; Beccai, L.; Mazzolai, B.; Shepherd, R. Highly stretchable electroluminescent skin for optical signaling and tactile sensing. Science 2016, 351, 1071-1074. [CrossRef]

20. An, B.W.; Heo, S.; Ji, S.; Bien, F.; Park, J.-U. Transparent and flexible fingerprint sensor array with multiplexed detection of tactile pressure and skin temperature. Nat. Commun. 2018, 9, 2458. [CrossRef]

21. Nie, B.; Li, R.; Cao, J.; Brandt, J.D.; Pan, T. Flexible Transparent Iontronic Film for Interfacial Capacitive Pressure Sensing. Adv. Mater. 2015, 27, 6055-6062. [CrossRef] [PubMed]

22. Boutry, C.M.; Negre, M.; Jorda, M.; Vardoulis, O.; Chortos, A.; Khatib, O.; Bao, Z. A hierarchically patterned, bioinspired e-skin able to detect the direction of applied pressure for robotics. Sci. Robot. 2018, 3, eaau6914. [CrossRef]

23. Mannsfeld, S.C.B.; Tee, B.C.K.; Stoltenberg, R.M.; Chen, C.V.H.H.; Barman, S.; Muir, B.V.O.; Sokolov, A.N.; Reese, C.; Bao, Z. Highly sensitive flexible pressure sensors with microstructured rubber dielectric layers. Nat. Mater. 2010, 9, 859-864. [CrossRef] [PubMed]

24. Taroni, P.J.; Santagiuliana, G.; Wan, K.; Calado, P.; Qiu, M.; Zhang, H.; Pugno, N.M.; Palma, M.; Stingelin-Stutzman, N.; Heeney, M.; et al. Toward Stretchable Self-Powered Sensors Based on the Thermoelectric Response of PEDOT:PSS/Polyurethane Blends. Adv. Funct. Mater. 2018, 28, 1704285. [CrossRef]

25. Zhang, D.; Song, Y.; Ping, L.; Xu, S.; Yang, D.; Wang, Y.; Yang, Y. Photo-thermoelectric effect induced electricity in stretchable graphene-polymer nanocomposites for ultrasensitive strain sensing. Nano Res. 2019, 12, 2982-2987. [CrossRef]

26. Wu, W.; Wen, X.; Wang, Z.L. Taxel-Addressable Matrix of Vertical-Nanowire Piezotronic Transistors for Active and Adaptive Tactile Imaging. Science 2013, 340, 952-957. [CrossRef]

27. Wu, W.; Wang, L.; Li, Y.; Zhang, F.; Lin, L.; Niu, S.; Chenet, D.; Zhang, X.; Hao, Y.; Heinz, T.F.; et al. Piezoelectricity of single-atomic-layer MoS2 for energy conversion and piezotronics. Nature 2014, 514, 470-474. [CrossRef]

28. Pan, C.; Chen, M.; Yu, R.; Yang, Q.; Hu, Y.; Zhang, Y.; Wang, Z.L. Progress in Piezo-Phototronic-Effect-Enhanced Light-Emitting Diodes and Pressure Imaging. Adv. Mater. 2016, 28, 1535-1552. [CrossRef]

29. Bao, R.; Wang, C.; Dong, L.; Shen, C.; Zhao, K.; Pan, C. CdS nanorods/organic hybrid LED array and the piezo-phototronic effect of the device for pressure mapping. Nanoscale 2016, 8, 8078-8082. [CrossRef]

30. Hassan, K.; Amir, R.; Majid, E.W.; Ajay, K.; Mohsen, A. Sensitive and flexible polymeric strain sensor for accurate human motion monitoring. Sensors 2018, 18, 418. [CrossRef]

31. Lin, Z.H.; Zhu, G.; Zhou, Y.S.; Yang, Y.; Bai, P.; Chen, J.; Wang, Z.L. A self-powered triboelectric nanosensor for mercury ion detection. Angew. Chem. Int. Ed. Engl. 2013, 52, 5065-5069. [CrossRef] [PubMed]

32. Zhong, Q.; Zhong, J.; Hu, B.; Hu, Q.; Zhou, J.; Wang, Z.L. A paper-based nanogenerator as a power source and active sensor. Energy Environ. Sci. 2013, 6, 1779-1784. [CrossRef]

33. Yi, F.; Lin, L.; Niu, S.; Po, K.Y.; Wang, Z.; Chen, J.; Zhou, Y.; Zi, Y.; Wang, J.; Liao, Q.; et al. Stretchable-Rubber-Based Triboelectric Nanogenerator and its application as self-powered body motion sensors. Adv. Funct. Mater. 2015, 25, 3688-3696. [CrossRef]

34. Wang, X.; Zhang, H.; Dong, L.; Han, X.; Du, W.; Zhai, J.; Pan, C.; Wang, Z.L. Self-Powered High-Resolution and Pressure-Sensitive Triboelectric Sensor Matrix for Real-Time Tactile Mapping. Adv. Mater. 2016, 28, 2896-2903. [CrossRef] [PubMed]

35. Wang, X.; Zhang, Y.; Zhang, X.; Huo, Z.; Li, X.; Que, M.; Peng, Z.; Wang, H.; Pan, C. A Highly Stretchable Transparent Self-Powered Triboelectric Tactile Sensor with Metallized Nanofibers for Wearable Electronics. Adv. Mater. 2018, 30, 1706738. [CrossRef] [PubMed]

36. Sekitani, T.; Yokota, T.; Zschieschang, U.; Klauk, H.; Bauer, S.; Takeuchi, K.; Takamiya, M.; Sakurai, T.; Someya, T. Organic Nonvolatile Memory Transistors for Flexible Sensor Arrays. Science 2009, 326, 1516-1519. [CrossRef]

37. Zang, Y.; Zhang, F.; Huang, D.; Gao, X.; Di, C.-A.; Zhu, D. Flexible suspended gate organic thin-film transistors for ultra-sensitive pressure detection. Nat. Commun. 2015, 6, 6269. [CrossRef]

38. Wang, C.; Hwang, D.; Yu, Z.; Takei, K.; Park, J.; Chen, T.; Ma, B.; Javey, A. User-interactive electronic skin for instantaneous pressure visualization. Nat. Mater. 2013, 12, 899-904. [CrossRef] 
39. Arnaldo, G.L.-J.; Anselmo, F.; Rui, M.; Maria, J.P.; Andrea, F.; Getinet, T.W.; Ole, B.; Carlos, M. Influence of the cladding structure in PMMA mPOFs mechanical properties for strain sensors applications. IEEE Sens. J. 2018, 18, 5805-5811. [CrossRef]

40. Arnaldo, L.-J.; Anselmo, F.; Carlos, M.; Maria, J.P. Polymer-optical-fiber-based sensor system for simultaneous measurement of angle and temperature. Appl. Opt. 2018, 57, 1717-1723. [CrossRef]

41. Arnaldo, L.-J.; Anselmo, F.-N.; Carlos, M.; Maria, J.P. Measurement of temperature and relative humidity with polymer optical fiber sensors based on the induced stress-optic effect. Sensor 2018, 18, 916. [CrossRef]

42. Lee, J.; Pyo, S.; Kwon, D.-S.; Jo, E.; Kim, W.; Kim, J. Ultrasensitive Strain Sensor Based on Separation of Overlapped Carbon Nanotubes. Small 2019, 15, 1805120. [CrossRef] [PubMed]

43. Shi, X.; Wang, H.; Xie, X.; Xue, Q.; Zhang, J.; Kang, S.; Wang, C.; Liang, J.; Chen, Y. Bioinspired Ultrasensitive and Stretchable MXene-Based Strain Sensor via Nacre-Mimetic Microscale "Brick-and-Mortar" Architecture. ACS Nano 2019, 13, 649-659. [CrossRef] [PubMed]

44. Yang, T.; Li, X.M.; Jiang, X.; Lin, S.; Lao, J.; Shi, J.; Zhen, Z.; Li, Z.; Zhu, H. Structural engineering of gold thin films with channel cracks for ultrasensitive strain sensing. Mater. Horiz. 2016, 3. [CrossRef]

45. Wu, J.; Wu, Z.; Lu, X.; Han, S.; Yang, B.-R.; Gui, X.; Tao, K.; Miao, J.; Liu, C. Ultrastretchable and Stable Strain Sensors Based on Antifreezing and Self-Healing Ionic Organohydrogels for Human Motion Monitoring. ACS Appl. Mater. Interfaces 2019, 11, 9405-9414. [CrossRef]

46. Zhou, C.-G.; Sun, W.-J.; Jia, L.-C.; Xu, L.; Dai, K.; Yan, D.-X.; Li, Z.-M. Highly Stretchable and Sensitive Strain Sensor with Porous Segregated Conductive Network. ACS Appl. Mater. Interfaces 2019, 11, 37094-37102. [CrossRef]

47. Zhou, Y.; Wan, C.; Yang, Y.; Yang, H.; Wang, S.; Dai, Z.; Ji, K.; Jiang, H.; Chen, X.; Long, Y. Highly Stretchable, Elastic, and Ionic Conductive Hydrogel for Artificial Soft Electronics. Adv. Funct. Mater. 2019, 29, 180622. [CrossRef]

48. Seyedin, S.; Razal, J.M.; Innis, P.C.; Jeiranikhameneh, A.; Beirne, S.; Wallace, G.G. Knitted Strain Sensor Textiles of Highly Conductive All-Polymeric Fibers. ACS Appl. Mater. Interfaces 2015, 7, 21150-21158. [CrossRef]

49. Lipomi, D.J.; Lee, J.A.; Vosgueritchian, M.; Tee, B.C.K.; Bolander, J.A.; Bao, Z. Electronic Properties of Transparent Conductive Films of PEDOT:PSS on Stretchable Substrates. Chem. Mater. 2012, 24, 373-382. [CrossRef]

50. Hempel, M.; Nezich, D.; Kong, J.; Hofmann, M. A novel class of strain gauges based on layered percolative films of 2D materials. Nano Lett. 2012, 12, 5714-5718. [CrossRef]

51. Bai, L.; Xu, Y.; Jiang, Y.; Chen, H.; Li, X.; Zhang, J.; Song, G. Transfer method of crumpled graphene and its application for human strain monitoring. Sens. Actuator A Phys. 2017, 260, 153-160. [CrossRef]

52. Yao, S.; Zhu, Y. Wearable multifunctional sensors using printed stretchable conductors made of silver nanowires. Nanoscale 2014, 6, 2345-2352. [CrossRef] [PubMed]

53. Qi, D.; Liu, Z.; Yu, M.; Liu, Y.; Tang, Y.; Lv, J.; Li, Y.; Wei, J.; Liedberg, B.; Yu, Z.; et al. Highly Stretchable Gold Nanobelts with Sinusoidal Structures for Recording Electrocorticograms. Adv. Mater. 2015, 27, 3145-3151. [CrossRef] [PubMed]

54. Zhang, B.-C.; Wang, H.; Zhao, Y.; Li, F.; Ou, X.-M.; Sun, B.-Q.; Zhang, X.-H. Large-scale assembly of highly sensitive Si-based flexible strain sensors for human motion monitoring. Nanoscale 2016, 8, 2123-2128. [CrossRef] [PubMed]

55. Kim, H.-J.; Thukral, A.; Yu, C. Highly Sensitive and Very Stretchable Strain Sensor Based on a Rubbery Semiconductor. ACS Appl. Mater. Interfaces 2018, 10, 5000-5006. [CrossRef]

56. Roh, E.; Hwang, B.-U.; Kim, D.; Kim, B.-Y.; Lee, N.-E. Stretchable, Transparent, Ultrasensitive, and Patchable Strain Sensor for Human-Machine Interfaces Comprising a Nanohybrid of Carbon Nanotubes and Conductive Elastomers. ACS Nano 2015, 9, 6252-6261. [CrossRef]

57. Liu, J.; Guo, Q.; Mao, S.; Chen, Z.; Zhang, X.; Yang, Y.; Zhang, X. Templated synthesis of a 1D Ag nanohybrid in the solid state and its organized network for strain-sensing applications. J. Mater. Chem. C 2018, 6, 10730-10738. [CrossRef]

58. Zang, J.; Ryu, S.; Pugno, N.; Wang, Q.; Tu, Q.; Buehler, M.J.; Zhao, X. Multifunctionality and control of the crumpling and unfolding of large-area graphene. Nat. Mater. 2013, 12, 321-325. [CrossRef] 
59. Wang, Z.; Zhang, L.; Liu, J.; Li, C. Highly Stretchable, Sensitive, and Transparent Strain Sensors with a Controllable In-Plane Mesh Structure. ACS Appl. Mater. Interfaces 2019, 11, 5316-5324. [CrossRef]

60. Sun, H.; Zhou, K.; Yu, Y.; Yue, X.; Dai, K.; Zheng, G.; Liu, C.; Shen, C. Highly Stretchable, Transparent, and Bio-Friendly Strain Sensor Based on Self-Recovery Ionic-Covalent Hydrogels for Human Motion Monitoring. Macromol. Mater. Eng. 2019, 304, 1900227. [CrossRef]

(C) 2020 by the authors. Licensee MDPI, Basel, Switzerland. This article is an open access article distributed under the terms and conditions of the Creative Commons Attribution (CC BY) license (http://creativecommons.org/licenses/by/4.0/). 